\title{
Residentes em saúde da família na assistência à paciente na pandemia: um relato de experiência
}

\author{
Family health residents in patient care in the pandemic: an experience report \\ Residentes de salud familiar en atención al paciente en la pandemia: informe de experiencia
}

\begin{abstract}
RESUMO
OBJETIVO: Relatar a atuação dos residentes do Programa em Saúde da Família na assistência a pacientes no contexto da infecção de Sars-CoV-2. MÉTODOS: Trata-se de um estudo descritivo do tipo relato de experiência, realizado na Unidade Básica de Saúde da Família (UBS) destinada ao atendimento de pacientes sintomáticos respiratórios, delineado do mês de julho a dezembro de 2020. RESULTADOS: A UBS passou a ser referência no município para assistência de pacientes portadores de sintomas respiratórios, promovendo o diagnóstico e tratamento do COVID-19. CONCLUSÃO: Baseado no relato descrito, é possivel confirmar que a experiência vivenciada, além de contribuir para o aprendizado dos residentes multiprofissionais, colaborou significativamente com o êxito das ações exercidas.

DESCRITORES: Atenção Primária à Saúde; COVID-19; Residência não Médica
\end{abstract}

\section{ABSTRACT}

OBJECTIVE: To report the performance of residents of the Family Health Program in patient care in the context of Sars-CoV-2 infection. METHODS: This is a descriptive study of the experience report type, carried out at the Basic Family Health Unit (UBS) for the care of symptomatic respiratory patients, delineated from July to December 2020. RESULTS: The UBS became to be a reference in the city for the care of patients with respiratory symptoms, promoting the diagnosis and treatment of COVID-19. CONCLUSION: Based on the report described, it is possible to confirm that the lived experience, in addition to contributing to the learning of multidisciplinary residents, significantly contributed to the success of the actions performed.

DESCRIPTORS: Primary Health Care; COVID-19; Non-Medical Residence.

\section{RESUMEN}

OBJETIVO: Reportar el desempeño de los residentes del Programa de Salud de la Familia en la atención al paciente en el contexto de la infección por Sars-CoV-2. MÉTODOS: Se trata de un estudio descriptivo del tipo relato de experiencia, realizado en la Unidad Básica de Salud de la Familia (UBS) para la atención de pacientes respiratorios sintomáticos, delineado de julio a diciembre de 2020. RESULTADOS: La UBS se convirtió en un referente en el ciudad para la atención de pacientes con síntomas respiratorios, promoviendo el diagnóstico y tratamiento del COVID-19. CONCLUSIÓN: Con base en el informe descrito, es posible constatar que la experiencia vivida, además de contribuir al aprendizaje de los residentes multidisciplinares, contribuyó significativamente al éxito de las acciones realizadas.

DESCRIPTORES: Atención Primaria de Salud; COVID-19; Residencia no médica.

RECEBIMENTO: 18/09/2020 APROVAÇÃO: 30/09/2020

\section{Daniella Dias Takemoto de Arruda}

Enfermeira, Residente do Programa Multiprofissional em Atenção Básica da Faculdade de Medicina de São José do Rio Preto - São José do Rio Preto (SP), Brasil.

ORCID: 0000-0001-5463-1308.

\section{Francisca Geisa Silva Martiniano}

Discente do Curso de Enfermagem no Centro Universitário INTA - Sobral (CE), Brasil.

ORCID: 0000-0001-5176-7939.

\section{Gabriely Cristina Pereira Maranduba}

Enfermeira. Residente em Saúde da Família pela Faculdade de Medicina de São José do Rio Preto - São José do Rio Preto (SP), Brasil.

Orcid: 0000-0003-3127-4242. 


\section{Karine Eduarda de Oliveira}

Enfermeira, Residente em Saúde da Família pela Faculdade de Medicina de São José do Rio Preto - São José do Rio Preto (SP), Brasil.

Orcid: 0000-0003 4647-6808.

\section{Maria José Dias Gonzaga}

Enfermeira, Mestranda em Enfermagem na Saúde do Adulto na Universidade de São Paulo - São Paulo (SP), Brasil. Orcid: 0000-0003-4558-4778.

\section{Ana Lúcia Siqueira Costa Calache}

Enfermeira. Doutorado em Enfermagem na Saúde do Adulto na Universidade de São Paulo - São Paulo (SP), Brasil. Professor Associada Sênior do Departamento de Enfermagem Médico- Cirúrgico na Escola de Enfermagem da Universidade de São Paulo.

ORCID: 0000-0001-7830-9751.

\section{INTRODUÇÃO}

$\mathbf{M}$ anifestado no final do ano de 2019, o novo coronavírus, agente causador de um acervo de casos de pneumonia na China, foi nomeado de SARS-CoV-2. No entanto, não existe informação plena sobre a história natural a respeito da doença. Evidenciou-se que o vírus apresenta alta transmissibilidade e ocasiona uma Síndrome Respiratória Aguda Grave (SRAG) que pode variar de casos leves, cerca de $80 \%$ dos casos, muito grave, entre $5 \%$ e $10 \%$, que podem progredir para insuficiência respiratória(1). Embora a pandemia tenha iniciado na China em dezembro de 2019, no Brasil, o primeiro episódio foi evidenciado e notificado em março de 2020(2).

Á vista disso, a Organização Mundial de Saúde (OMS) anunciou no dia 11 de março que o mundo estaria em uma situação pandêmica(3). Em função desta realidade, foram estabelecidas medidas de modo a reduzir a transmissão viral. Estas medidas de segurança incluem: adesão a máscaras, higienização das mãos, limpeza abundante de superfícies, etiqueta respiratória, vigilância de fronteiras e cessação do funcionamento de comércios julgados não essenciais, sendo exemplos de providências não farmacológicas que foram propostas para controle dos altos índices de contaminação(4).

A velocidade da transmissão entre os países resultou em pandemia, atribuída à comunicação próxima de indivíduos contaminados, manifestações de sintomas, trajeto de pessoas em ambientes sem circulação de $\operatorname{ar}(5)$. Lamentavelmente, não existiu uma conduta global padronizada para o enfrentamento do COVID-19. Cada país lidou com a pandemia de acordo com as competências, alternativas e hipóteses evidenciadas por meio de suas respectivas vigilâncias epidemiológicas. Como desfecho da carência de resolução, os países apresentaram velocidades distintas em relação à transmissão da doença, cujos alguns apresentaram considerável sucesso no manejo da doença em sua população, enquanto outros não, embora com praticadas correta, porém com pouca resolutividade(6).

As providências adotadas para o controle do vírus refletiram em diferentes instâncias da sociedade, especialmente na esfera da saúde, que se direcionou a assistência prestada aos casos suspeitos ou confirmada, bem como a necessidade de recursos humanos, materiais e leitos disponíveis em Unidade de Terapia Intensiva(7). Entretanto, além da assistência médica, foi necessário concentrar tentativas para controle eficaz da pandemia, por meio de ações direcionadas para a população, com o intuito de protegê-las da transmissão, com a identificação de os sinais e sintomas de forma precoce, isolamento social, monitoramento do caso e dos contatos domiciliares, tratamento e reabilitação dos acometidos(8).

Combater a atual pandemia exige uma conduta comunitária, promocional, territorial e inclusiva de vigilância em saúde(8). Neste sentido, destaca-se a Atenção Primária à Saúde como porta de entrada á Rede de Atenção à Saúde, com estabelecimento de estratégias que visem o alcance de resul- tados efetivos durante a pandemia, na construção de intervenções resolutivas e eficazes nos casos leves e moderados de COVID-19, assim como no reconhecimento e direcionamento de casos graves para os níveis mais complexos de atenção(7).

Em face do exposto, este trabalho tem como objetivo relatar a atuação dos residentes multiprofissional do programa em Atenção Básica na Assistência no contexto da infecção de SARS-CoV-2.

\section{MÉTODOS}

Trata-se de um estudo descritivo, do tipo de relato de experiência, este tem como objetivo descrever as características de determinado cenário, evento ou população(9). O Cenário foi uma Unidade Básica de Saúde da Família (UBSF) de um município localizado no noroeste paulista, campo de práticas de residentes multiprofissionais. A unidade abrange uma população estimada de 15.898 mil usuários, conta com três equipes de saúde da família e nelas inseridas, três Enfermeiros, dois Médicos Obstétricas, três Clínicos e dois Pediatras.

As atividades foram desenvolvidas em uma UBSF, realizada a partir da vivência de residentes multiprofissionais em atenção básica com ênfase na estratégia de saúde da família, delineado entre os meses de julho a dezembro de 2020. Dentre os profissionais envolvidos, destacam-se os enfermeiros, técnicos de enfermagem, residentes multiprofissionais e médicos.

A unidade refere-se a um serviço destinado ao atendimento de saúde da família 
na comunidade que, seguindo a regulamentação do município, passou a ser unidade de referência para síndrome respiratória, cujo atendimento se tornou exclusivamente para suspeitos e confirmados de COVID-19.

Utilizou-se como critérios de inclusão, os relatos, as observações, as experiências vivenciadas pelos residentes em saúde da família diante de suas atuações e atividades desenvolvidas, considerando a atuação na assistência, de pessoas, materiais e fluxos frente à pandemia da COVID-19, bem como suas vivências associadas as mudança no processo de trabalho e os desafios de nova rotina.

Para coleta das informações foi utilizada a observação participante, consolidada em anotaçôes de um diário de campo. As informações foram analisadas criticamente a partir da fundamentação teórica prévia dos autores sobre os campos da COVID-19 e atenção primária.

\section{ROTEIRO DE ASSISTÊNCIA}

O cenário de pandemia exigiu adaptação e reorganização assistencial e estrutural nas instituições e serviços de todos os níveis de complexidade, criação de alas de isolamento, organização de fluxos assistenciais, elaboração de protocolos, remanejamento de profissionais, desenvolvimento de educação permanente, ações necessárias para atender a população $(10,11)$.

No dia 14 de julho de 2020, a Unidade Básica de Saúde, que até o momento se tratava de um serviço destinado ao atendimento de saúde da família na comunidade, passou a ser referência no município para assistência de pacientes portadores de sintomas respiratórios, cujas atividades se concentraram na promoção do diagnóstico e tratamento do COVID-19. Logo, devido à demanda da população, a extensão do horário de atendimento, bem como o fato dos profissionais pertencentes ao grupo de risco serem transferidos para serviços não remetidos ao atendimento de sintomáticos respiratórios, houve a necessidade de se inserir novos funcionários na unidade, dentre eles enfermeiros, técnicos de enfermagem, assistentes administrativos e médicos.
Lamentavelmente, não existiu uma

\section{conduta global}

padronizada para

o enfrentamento

do COVID-19.

Cada país lidou

com a pandemia

de acordo com

as competências,

alternativas

e hipóteses

evidenciadas

por meio de

suas respectivas

vigilâncias

epidemiológicas
Inicialmente, realizou-se uma reunião com os profissionais e residentes da unidade, a fim de esclarecer os protocolos, definir organização do fluxo interno de atendimento e divisão dos funcionários com suas devidas funções. Diante disso, foi estabelecido uma rotina de educação permanente com os profissionais da saúde de acordo conforme a aprovação dos decretos municipais.

$\mathrm{Na}$ atenção primária à saúde foi instituída um fluxo de atendimento, em que o usuário antes de adentrar unidade, era recebido na porta de entrada pelo profissional da saúde devidamente capacitado, com a finalidade do esclarecer as possíveis dúvidas, identificar presença de queixas respiratórias (tosse, febre, coriza, odinofagia, entre outros), direcionar o paciente a uma unidade adequada em caso de ausência dos sintomas, organizar a fila de espera e conduzir o paciente ao atendimento, realizando, então, a triagem precocemente. Logo após o paciente ser admitido, o atendimento era continuado pela Enfermeira Residente e Técnica de Enfermagem para realização do acolhimento e verificação dos sinais vitais. No acolhimento abordava-se o usuário sobre suas queixas, sintomas, início do quadro, comorbidades, alergias medicamentosas e alimentares, local de trabalho e função, contatos domiciliares, telefones atualizados, imunização contra influenza no ano de 2020 e se o paciente teve contato com casos confirmados para COVID-19, além de fornecer orientações relacionadas ao isolamento domiciliar, uso de máscara e higienização.

Após a triagem, o usuário que se apresentava estável, sem sinais aparente de gravidade, era encaminhado à sala de espera para aguardar o atendimento médico. Posterior à consulta médica e solicitação de exames, o usuário com sintomas leves, era encaminhado para sala de atendimento para que a enfermeira residente e enfermeira da unidade realizassem a notificação do caso na plataforma e-SUS para, a seguir, proceder à coleta de RT-PCR para confirmação da infecção por SARS-CoV-2.

Durante a notificação do caso a enfermeira era responsável por cadastrar a soli- 
citação do exame na rede de laboratórios e preencher a planilha utilizada para controle de coletas com os dados do paciente (nome completo, local de trabalho, telefones atualizados, data de início dos sintomas e critérios para monitoramento) e o resultado do exame. Para o acompanhamento do usuário foi utilizada a planilha adscritos a fim de comunicar os resultados de exames, manter a investigação, monitoramento do usuário e contatos domiciliares, com destaque dos pacientes com comorbidades (Hipertensão arterial, Diabetes Mellitus, Doenças Respiratórias Descompensadas, Imunossupressão, entre outros).

O usuário com alterações de sinais vitais, com diminuição da saturação de oxigênio, o valor menor ou igual a $94 \%$, era encaminhado para a sala de pronto atendimento da unidade, com o intuito de estabilizar de forma breve esta alteração. A sala de pronto atendimento continha equipe de assistência médica, equipe de enfermagem e equipamentos essenciais para ofertar cuidados aos pacientes graves.

Com aumento de usuários instáveis, estes que permaneciam acomodados no pronto atendimento da unidade aos cuidados da equipe de enfermagem e residentes. Nesse período de restabelecimento do quadro, o usuário era submetido a exames laboratoriais e medicações prescritas conforme a necessidade e, quando necessário era instalado oxigenioterapia com volume determinado de acordo com a saturação apresentada. Nos casos de pacientes com piora do quadro, o mesmo era encaminhado para uma unidade de internação através do Serviço de Atendimento Móvel de Urgência (SAMU). No entanto, devido ao aumento da demanda de casos de COVID-19, o SAMU não conseguia responder prontamente a regulação do paciente, e o usuário permanecia monitorado na unidade com assistência e orientação, a espera pela chegada da ambulância para o transporte à uma unidade hospitalar.

Nos casos em que o paciente comparecia a unidade com queixas iniciadas há 14 dias ou mais, a conduta era a realização de teste rápido para detecção de SARS-CoV-2. Após a realização do teste, o laudo era con- cedido, bem como o fornecimento das devidas orientações realizado pelas enfermeiras

Diante do exposto, as atribuições

\section{dos residentes}

contribuíram no

atendimento a

necessidade dos

usuários, além da

assistência direta,

acolhimento,

notificação dos

casos, coletas de

exame do PCR,

atualização diária da

planilha dos casos

de COVID-19

e residentes. Após a liberação do resultado, também era de responsabilidade do serviço atualizar a notificação, com informação se o caso suspeito havia se confirmado ou não.

\section{DISCUSSÃO}

Diante do exposto, as atribuições dos residentes contribuíram no atendimento a necessidade dos usuários, além da assistência direta, acolhimento, notificação dos casos, coletas de exame do PCR, atualização diária da planilha dos casos de COVID-19, monitoramento dos casos confirmados, avaliação das condutas tomadas e os desfechos, contato telefônico diário para acompanhamento dos usuários, comunicação dos resultados de exames, contato com os indivíduos de referência no domicílio e as orientações necessárias. Isso proporcionou monitoramento e identificação de casos leves, moderados e graves da doença, a orientação sobre o agravamento dos sintomas e $\mathrm{o}$ retorno imediato ao serviço de saúde para reavaliação, quando necessário.

Observou-se uma atuação ativa dos residentes na unidade de atendimento para pacientes suspeitos e confirmados de $\mathrm{CO}$ VID-19 e a vivência do aprendizado das situações de urgência e emergência na atenção primaria à saúde.

Ficou evidenciada a adesão dos residentes na implementação do novo fluxo atendimento, na assistência aos usuários, no uso de equipamentos de proteção individual e na resolução às demais demandas exercidas, com conhecimento e senso de responsabilidade. As realizações de atividades auxiliam o bem-estar da vida dos usuários a partir de uma prática multiprofissional, favorecendo, a atuação colaborativa entre os profissionais da saúde e promovendo a integralidade do cuidado que é fundamental para o fortalecimento do SUS(12).

Os residentes contaram com o apoio dos enfermeiros, da equipe saúde da família e gestores na constante supervisão, o qual proporcionou autonomia e o desenvolvimento de capacitação para o exercício de atividade e função embasado no conhecimento científico. Assim, ao atuar em equipes multiprofissionais, tem-se a valorização do papel de cada profissional favorecendo, dessa forma, uma assistência qualificada, 
o trabalho coletivo e a oportunidade de novos conhecimentos acerca de outras áreas $(13,14)$.

Dessa forma, visto que a atuação dos residentes em conjunto com os profissionais da saúde na UBS favoreceu o processo de trabalho, a qualidade do cuidado e segurança do paciente.

\section{CONCLUSÃO}

Ao relatar a experiência vivenciada no cenário da atual pandemia, vimos à diver- sidade existente nas mesmas e suas potências, reconhecidas por meio das estratégias adotadas, como o planejamento, no qual a protagonista é a equipe de saúde em família, que junto com os residentes multiprofissionais tiveram parceria com a gestão e a sociedade.

Baseado no relato descrito, é possível confirmar que a experiência vivenciada, contribuiu para a formação dos residentes colaborou significativamente com o êxito das práticas, proporcionou atuação com equipe multiprofissional e fornecimento de uma assistência segura e de qualidade ao usuário. Portanto, o vínculo estabelecido entre todos os profissionais, que incluíram os residentes na rotina do serviço através do programa, foi alicerce fundamental para a implementação de novas estratégias e fluxos de atendimentos, especialmente em período pandêmico como atualmente vivenciado.

Considera-se a capacidade de resiliência e reinvenção dos profissionais e a importância dessa força de trabalho para a comunidade.

\section{REFERÊNCIAS}

1. Ministério da Saúde (Brasil). Secretaria de Atenção Primária à Saúde. Protocolo de manejo clínico do coronavírus (COVID-19) na Atenção Primária à Saúde. Versão 9. Brasília: Ministério da Saúde; maio de 2020. $9^{a}$ versão. [cited 2021 jan 12]; Disponivel em: https:// www.unasus.gov.br/especial/covid19/pdf/37.

2. Vianna LS, Busana JA. Predição de casos de COVID-19 nos municípios de Santa Catarina utilizando redes neurais recorrentes. Revista de Saúde Coletiva (Barueri). 2021; 11(67); 6851-6862. Disponível em: http://revistas.mpmcomunicacao.com.br/index.php/saudecoletiva/article/view/1734/2022.

3. Sarti TD, Lazarini WS, Fontenelle LF, Almeida APSC. Qual é o papel da Atenção Primária à Saúde diante da pandemia provocada pela COVID-19? Epidemiol. Serv. Saúde. Brasília, 2020; 29(2): 1-5. Disponivel em: https://www.scielo.br/scielo.php?script=sci_arttext\&pid=S2237-96222020000200903.

4. Almeida JS, Cardoso JA, Cordeiro EC, Lemos M, Araújo TME, Sardinha AHL. Caracterização epidemiológica dos casos de COVID-19 no Maranhão: uma breve análise. Ver Pre Infec e Saúde. 2020; 6: 1-11. [citado em 2021 jan. 13]; Disponível em: https://ojs.ufpi.br/index.php/ nupcis/article/download/10477/pdf.

5. David HMSL, Acioli S, Silva MRF, Bonetti OP, Passos H. Pandemia, conjuntura de crises e prática profissional: qual o papel da enfermagem diante da COVID-19? Rev Gaúcha Enferm. 2021; 42:1-7. [citado em 2021 jan. 15]. doi: 10.1590/1983- 1447.2021.20190254. Disponivel em: https://www.scielo.br/pdf/rgenf/v42nspe/pt_19831447-rgenf-42-spe-e20200254.pdf.

6. Houvèssou GM, Souza TP, Silveira MF. Medidas de contenção de tipo lockdown para prevenção e controle da COVID-19: estudo ecológico descritivo, com dados da África do Sul, Alemanha, Brasil, Espanha, Estados Unidos, Itália e Nova Zelândia, fevereiro a agosto de 2020. Epidemiol. Serv. Saude. Brasília, 2021; 30(1): 1-12. [citado em 2021 jan. 15]; Disponível em: https://www.scielo.br/pdf/ress/v30n1/22379622-ress-30-01-e2020513.pdf.
7. Souza SS, Cunha AC, Suplici SER, Zamprogna KM, Laurindo DLP. Influência da cobertura da Atenção Básica no enfrentamento da COVID-19. Journal Health NPEPS. 2021 jan-jun; 6(1):1-21. [citado em 2021 jan. 16]; Disponível em: https://periodicos.unemat.br/index.php/ jhnpeps/article/view/4994/3938.

8. Giovanella L, Vega R, Tejerina-Silva H, Acosta-Ramirez N, Parada-Lezcano M, RÍOS G, et al. Es la atención primaria de salud integral parte de la respuesta a la pandemia de Covid-19 en Latinoamérica? Trab. Educ. Saúde online; 2021; 19. [citado em 2021 jan. 16]; doi: 10.1590/1981-7746-sol00310. Disponivel em: https://www.scielo. br/scielo.php?script=sci_arttext\&pid=S1981-77462021000100402.

9. Gil AC. Como elaborar projetos de pesquisa. 4. ed. São Paulo, Brasil: Atlas; 2008.

10. Medeiros EAS. A luta dos profissionais de saúde no enfrenta-mento da COVID-19. Acta Paul. Enferm. [Internet]. 2020. [acesso em 10 de agosto de 2021]. 33: e-EDT20200003.

11. Rodrigues AKS, Oliveira Junior LB, Vieira BB, Camila R. Desa-fios da gestão de hospitais públicos brasileiros no cenário da pandemia COVID-19. HU Rev. [Internet]. 2020. [acesso em 10 de agosto de 2021]. 46: 1-2.

12. Casanova IA, Batista NA, Ruiz-Moreno L. Residência multiprofissional em saúde: Percepção dos residentes sobre a Educação Interprofissional nas práticas colaborativas. In: Anais do $4^{\circ}$ Congresso Ibero-Americano em Investigação Qualitativa, 2015; Aracaju. Aracaju: CIAIQ; 2015. p. 368-370.

13. Silva JC, Contim D, OhI RIB, Chavaglia SRR, Amaral EMS. Percepção dos residentes sobre sua atuação no programa de residência multiprofissional. Acta Paul Enferm. 2015 mar/abr; 28(2):132-8.

14. Domingos CM, Nunes EFPA, Carvalho BG. Potencialidades da residência multiprofissional em saúde da família: 0 olhar do trabalhador de saúde. Interface 2015 out/dez;19(55):1221-32. 